\title{
Mutu Pelayanan Voluntary Counseling and Testing (VCT) di Klinik VCT Puskesmas Puger dari Perspektif Provider
}

\section{(Quality of Voluntary Counseling and Testing (VCT) Service at the VCT Clinic of Puger Primary Health Care from Provider Perspective)}

\author{
Indah Ernawati ${ }^{1}$, Christyana Sandra ${ }^{2}$, Yennike Tri Herawati ${ }^{3}$ \\ ${ }^{1,2,3}$ Bagian Administrasi dan Kebijakan Kesehatan, Fakultas Kesehatan Masyarakat, Universitas Jember \\ JI. Kalimantan 37, Jember 68121 \\ e-mail: indah.ernawati.18@gmail.com
}

\begin{abstract}
Voluntary Counseling and Testing (VCT) is an entry point to help everyone in utilizing services related to HIV-AIDS prevention, care, support and treatment. Puger Primary Health Care is a primary health care located in the work area with the highest number of HIV-AIDS sufferers in Jember Regency, experiencing a decrease in client visits, and there are some management services that are still not in accordance with VCT guidelines. This study aimed to describe the quality of VCT services at the VCT Clinic Puger Primary Health Care from the perspective of provider. This study was descriptive study using questionnaire, documentation study, and observation. The study respondents were 7 VCT clinic officers. The results indicated that in input parameter showed a lack of human resources, insufficient funding, lack of availability and material conditions that meet the VCT guidelines. In planning indicators related to the human resources, improvements of infrastructure facilities had not been written in the POA, the job description was sufficient based on duties and competences of staff and there were coordination, supervision and evaluation. In the dimensions of technical competence, access to services, efficiency, human relations, continuity and safety of VCT clinics in good categories, but sufficient and less categories for dimensions of effectiveness and comfort dimensions.
\end{abstract}

Keywords: VCT, Quality service, Provider perspective

\begin{abstract}
Abstrak
Voluntary Counseling and Testing (VCT) merupakan pintu masuk untuk membantu setiap orang dalam pemanfaatan layanan terkait dengan pencegahan, perawatan, dukungan, dan pengobatan HIV-AIDS. Puskesmas Puger adalah puskesmas dengan jumlah penderita HIV-AIDS tertinggi di Jember dan mengalami penurunan kunjungan klien. Terdapat beberapa pelayanan yang belum sesuai pedoman VCT. Penelitian ini bertujuan untuk menggambarkan mutu pelayanan VCT di Klinik VCT Puskesmas Puger dari perspektif provider. Ini adalah penelitian deskriptif menggunakan kuesioner, studi dokumentasi, dan observasi. Responden berjumlah 7 orang petugas klinik VCT. Hasil penelitian pada indikator input terdapat kurangnya SDM, pendanaan belum mencukupi, ketersediaan dan kondisi material belum memenuhi pedoman VCT. Pada perencanaan terkait penambahan SDM, perbaikan dan penambahan sarana prasarana belum tertulis dalam POA, pembagian kerja sudah sesuai tupoksi dan kompetensi petugas serta selalu dilakukan koordinasi, supervisi dan evaluasi, terdapat beberapa hal yag belum sesuai pedoman pada pelaksanaan layanan VCT. Pada dimensi kompetensi teknis, akses terhadap layanan, efisiensi, hubungan antar manusia, kontinuitas dan keamanan klinik VCT dalam kategori baik, tetapi pada dimensi efektivitas pelayanan dan dimensi kenyamanan dalam kategori cukup dan kurang.
\end{abstract}

Kata kunci: VCT, mutu pelayanan, perspektif provider 


\section{Pendahuluan}

HIV-AIDS salah satu masalah kesehatan terbesar yang dihadapi komunitas global dan menjadi perhatian khusus hingga saat ini. Data Dinas Kesehatan Kabupaten Jember pada tahun 2004 sampai Maret 2018 jumlah kumulatif ODHA telah mencapai 3.786 orang. Sementara, jumlah ODHA tertinggi di Kabupaten Jember berada di Kecamatan Puger yakni sebesar $10,7 \%$. Salah satu upaya yang dilakukan puskesmas ialah deteksi dini untuk mengetahui status HIV seseorang melalui layanan VCT. Voluntary Counseling and Testing (VCT) merupakan pintu masuk untuk membantu setiap orang dalam pemanfaatan layanan pencegahan, perawatan, dukungan, dan pengobatan [1].

Puskesmas Puger merupakan puskesmas yang berada di wilayah kerja dengan jumlah penderita HIV-AIDS tertinggi di Kabupaten Jember. Di Klinik VCT Puskesmas Puger terdapat beberapa penatalaksanaan pelayanan VCT dan sarana prasarana yang masih belum sesuai dengan pedoman pelaksanaan VCT. Selain itu, kunjungan klien mengalami penurunan dari 1.379 di tahun 2015 menjadi 550 di tahun 2016. Terjadinya penurunan jumlah kunjungan dan penatalaksanaan pelayanan yang belum sesuai pedoman tersebut perlu diperhatikan karena akan memberikan dampak terhadap mutu pelayanan klinik VCT Puskesmas Puger.

Penilaian mutu dari perspektif provider dapat dijadikan sebagai bahan perencanaan peningkatan mutu pelayanan yang saling mendukung dengan perspektif pelanggan eksternal. Tujuan dari penelitian ini untuk menggambarkan mutu pelayanan VCT Klinik VCT Puskesmas Puger dari perspektif provider.

\section{Metode Penelitian}

Penelitian ini merupakan jenis penelitian deskriptif, dilakukan di Klinik VCT Puskesmas Puger pada Oktober 2018. Unit analisis dalam penelitian ini ialah petugas klinik VCT sebanyak 7 responden.

Teknik pengumpulan data menggunakan kuesioner, studi dokumentasi, dan observasi. Hasil penelitian disajikan dalam bentuk tabel, dijelaskan dalam bentuk teks dengan kata-kata berupa narasi.

\section{Hasil}

Input

a. Man (Sumber daya manusia)

Hasil Input dari faktor sumber daya manusia dapat dilihat pada tabel 1 .

Tabel. 1 Distribusi Man pada pelayanan VCT

\begin{tabular}{cclcc}
\hline No & Variabel & Kategori & Jumlah & $\begin{array}{c}\text { Persentase } \\
(\%)\end{array}$ \\
\hline 1 & Ketersediaan & Memenuhi & 0 & 0 \\
& SDM & Tidak & 7 & 100 \\
& & memenuhi & & \\
\hline 2 & Pengetahuan & Tinggi & 3 & 42,9 \\
& & Sedang & 4 & 57,1 \\
& & Rendah & 0 & 0 \\
\hline 3 & Pelatihan & Memadai & 5 & 71,4 \\
& & Tidak & 2 & 28,6 \\
& & memadai & & \\
\hline \multicolumn{3}{c}{ Total } & 7 & 100 \\
\hline
\end{tabular}

Hasil penelitian pada aspek man yaitu ketersediaan SDM petugas VCT tidak memenuhi terutama konselor dan manager kasus. Sebagian besar responden memiliki pengetahuan sedang. Pelatihan tidak memadai bagi 2 responden.

b. Money

Sumber biaya layanan VCT di Puskesmas Puger dari BOK, Global Fund, dan KPA. Dana BOK untuk kegiatan operasional VCT, dana Global Fund untuk bahan habis pakai dan mendukung kegiatan mobile VCT setiap 3 bulan sekali. Kegiatan mobile VCT juga mendapat dukungan dana dari KPA. Menurut responden, ketersediaan biaya untuk layanan VCT masih belum mencukupi.

c. Material

Tabel 2. Distribusi material pada pelayanan VCT

\begin{tabular}{lllcc}
\hline No & \multicolumn{1}{c}{ Variabel } & Kategori & $\begin{array}{c}\text { Juml } \\
\text { ah }\end{array}$ & $\begin{array}{c}\text { Persent } \\
\text { ase (\%) }\end{array}$ \\
\hline 1 & $\begin{array}{l}\text { Ruangan } \\
\text { memenuhi } \\
\text { standar }\end{array}$ & Ya & 1 & 14,3 \\
& Tidak & 6 & 85,7 \\
\hline 2 & $\begin{array}{l}\text { Kelengkapan } \\
\text { sarana sesuai } \\
\text { pedoman }\end{array}$ & Ya & 1 & 14,3 \\
& Tidak & 6 & 85,7 \\
\hline 3 & $\begin{array}{l}\text { Kondisi sarana } \\
\text { dalam kondisi } \\
\text { baik }\end{array}$ & Ya & 1 & 14,3 \\
& Kelengkapan & 6 & 85,7 \\
\hline 4 & Ya & 3 & 42,9 \\
\hline
\end{tabular}




\begin{tabular}{lllll}
\hline & $\begin{array}{l}\text { prasarana } \\
\text { sesuai } \\
\text { pedoman }\end{array}$ & Tidak & 4 & 57,1 \\
\hline 5 & Kondisi & Ya & 2 & 28,6 \\
& $\begin{array}{l}\text { prasarana } \\
\text { dalam kondisi }\end{array}$ & Tidak & 5 & 71,4 \\
& baik & & \\
\hline 6 & Rencana & Ya & 6 & 85,7 \\
& $\begin{array}{l}\text { perbaikan } \\
\text { sarana } \\
\text { prasarana }\end{array}$ & Tidak & 1 & 14,3 \\
& & & \\
\hline & & & 7 & 100 \\
\hline
\end{tabular}

Hasil penelitian ruangan tidak memenuhi standar, kelengkapan sarana belum sesuai pedoman dan kondisi sarana kurang baik, kelengkapan prasarana belum sesuai pedoman dan kondisi prasarana kurang baik.

d. Method

Tabel 3. Distribusi method pada pelayanan VCT

\begin{tabular}{lllcc}
\hline No & Variabel & Kategori & Jumlah & $\begin{array}{c}\text { Persentase } \\
(\%)\end{array}$ \\
\hline 1 & Keseuaian & Sesuai & 7 & 100 \\
& SOP & Tidak & 0 & 0 \\
\hline \multicolumn{2}{l}{ Total } & & 7 & 100 \\
\hline
\end{tabular}

\section{Proses}

\section{a. Perencanaan (Planning)}

Strategi yang dilakukan berdasarkan POA 2018 meliputi home visit ODHA, pertemuan rutin KDS guna meningkatkan kualitas hidup ODHA dengan supporting teman sebaya, internal meeting petugas kesehatan. Namun belum ada perencanaan penambahan SDM, perbaikan dan penambahan sarana prasarana yang belum tersedia. Berdasarkan hasil penelitian juga diketahui bahwa Klinik VCT Puskesmas Puger telah memiliki SOP berupa pedoman internal VCT yang mengacu pada Permenkes RI Nomor 74 Tahun 2014 dan Kepmenkes RI No. 1507/MENKES/SK/X/2015.

\section{b. Pengorganisasian (Organizing)}

Hasil penelitian diketahui bahwa terdapat pembagian kerja sesuai dengan tupoksi dan kompetensi serta terdapat dokumen tertulis job description masing-masing petugas VCT. Koordinasi pelaksanaan program pelayanan VCT selalu dilakukan serta dilakukan internal meeting setiap tiga bulan sekali agar komunikasi dan kerjasama antar petugas kesehatan tetap terjaga.

\section{c. Pelaksanaan (Actuating) Berdasarkan hasil observasi diketahui}

bahwa mayoritas tahap pelayanan telah sesuai dengan pedoman. Namun terdapat beberapa yang tidak dilaksanakan sesuai pedoman yakni pemberian informasi keuntungan diagnosis dini, konseling pasca testing untuk klien dengan hasil testing negatif/nonreaktif, dan informasi 24 jam pendampingan. Selain itu, pada mobile VCT ke populasi kunci dan tes HIV atas inisiasi petugas tidak dilakukan konseling pra testing.

\section{d. Pengawasan (Controlling)}

Pengawasan di klinik VCT Puskesmas Puger meliputi supervisi setiap satu bulan sekali dan evaluasi berkala (satu bulan sekali/tiga bulan sekali) atau tidak terjadwal. Evaluasi berkala terkait evaluasi yang ada hubungannya dengan keluhan klien, tindakan untuk keberlanjutan program, sedangkan evaluasi tidak terjadwal dilakukan apabila ada kendala dalam proses berjalannya program pada hari itu sehingga tidak terjadi kendala yang sama.

\section{Output}

\section{a. Kompetensi Teknis}

Hasil observasi diketahui bahwa terdapat beberapa tindakan petugas yang kurang sesuai dengan tupoksi, misalnya pengambilan darah klien untuk testing dilakukan oleh petugas manager kasus yang berlatarpendidikan SMA bukan perawat. Kemampuan, keterampilan, kejelasan informasi dan penampilan petugas dalam pelayanan VCT sudah baik, koordinasi dan kerjasama dengan pihak terkait cukup baik, pengawasan pelaksanaan kegiatan pelayanan oleh kepala klinik VCT dan ketua tim mutu masih kurang.

\section{b. Akses terhadap Layanan}

Tabel 4. Distribusi Jawaban responden terhadap akses layanan

\begin{tabular}{lllcc}
\hline No & Variabel & Kategori & $\begin{array}{c}\text { Jumla } \\
\mathrm{h}\end{array}$ & $\begin{array}{c}\text { Persent } \\
\text { ase }(\%)\end{array}$ \\
\hline 1 & Lokasi & Ya & 7 & 100 \\
& strategis & Tidak & 0 & 0 \\
\hline 2 & Kemudahan & Ya & 7 & 100 \\
& $\begin{array}{l}\text { prosedur } \\
\text { pelayanan }\end{array}$ & Tidak & 0 & 0 \\
& & & \\
\hline 3 & Kecepatan & Ya & 7 & 100 \\
& $\begin{array}{l}\text { prosedur } \\
\text { penerimaan }\end{array}$ & Tidak & 0 & 0 \\
& klien & & & \\
\hline 4 & Petugas & Ya & 5 & 71,4 \\
& mudah & Tidak & 2 & 28,6 \\
\hline
\end{tabular}


Ernawati, et al., Mutu Pelayanan Voluntary and Counseling (VCT) di Klinik VCT Puskesmas .....

dihubungi klien

Total

7

100

Hasil penelitian diketahui bahwa lokasi puskesmas strategis, prosedur pelayanan mudah dan cepat, namun beberapa petugas cukup sulit dihubungi klien serta nomor telepon untuk pengaduan klien belum tersedia.

c. Efektivitas

Tabel 5. Efektivits pelayanan VCT

\begin{tabular}{llc}
\hline No & \multicolumn{1}{c}{ Efektivitas } & Penilaian \\
\hline 1 & $\begin{array}{l}\text { Kesesuaian penanganan } \\
\text { dan perawatan dengan } \\
\text { kebutuhan klien }\end{array}$ & Baik \\
\hline 2 & $\begin{array}{l}\text { Ketepatan waktu jam } \\
\text { pelayanan }\end{array}$ & Cukup \\
\hline 3 & $\begin{array}{l}\text { Ketepatan dan } \\
\text { kecepatan dalam } \\
\text { pencatatan dan } \\
\text { pelaporan }\end{array}$ & Kurang \\
\hline 4 & $\begin{array}{l}\text { Prosedur pelayanan } \\
\text { yang berlaku }\end{array}$ & Baik \\
\hline
\end{tabular}

Hasil penelitian menunjukkan penanganan dan perawatan sudah sesuai dengan kebutuhan klien, waktu jam pelayanan sudah cukup tepat, dan prosedur pelayanan yang berlaku sudah baik. Sedangkan ketepatan dan kecepatan dalam pencatatan dan pelaporan masih kurang.

d. Efisiensi

Tabel 6. Distribusi Jawaban Responden terhadap Efisiensi.

\begin{tabular}{lllcc}
\hline No & Variabel & Kategori & $\begin{array}{c}\text { Jumla } \\
\mathrm{h}\end{array}$ & $\begin{array}{c}\text { Persent } \\
\text { ase }(\%)\end{array}$ \\
\hline 1 & Kecepatan & Ya & 7 & 100 \\
& pelayanan & Tidak & 0 & 0 \\
\hline 2 & SDM memadai & Ya & 0 & 0 \\
& & Tidak & 7 & 100 \\
\hline 3 & Persediaan & Ya & 1 & 14,3 \\
& peralatan & Tidak & 6 & 85,7 \\
& lengkap & & & \\
\hline \multicolumn{2}{l}{ Total } & & 7 & 100 \\
\hline
\end{tabular}

Hasil penelitian menunjukkan pelayanan yang diberikan cepat, SDM kurang memadai, dan persediaan peralatan kurang lengkap.

e. Hubungan Antar Manusia
Tabel 7. Distribusi Jawaban Responden terhadap Hubungan Antar Manusia

\begin{tabular}{|c|c|c|c|c|}
\hline No & Variabel & Kategori & $\underset{\mathrm{h}}{\mathrm{Jumla}}$ & $\begin{array}{l}\text { Persent } \\
\text { ase (\%) }\end{array}$ \\
\hline \multirow[t]{4}{*}{1} & Petugas & $\mathrm{Ya}$ & 7 & 100 \\
\hline & menerima dan & Kadang & 0 & 0 \\
\hline & mendengarkan & Tidak & 0 & 0 \\
\hline & $\begin{array}{l}\text { keluhan klien } \\
\text { dengan baik }\end{array}$ & & & \\
\hline \multirow[t]{5}{*}{2} & Petugas & $\mathrm{Ya}$ & 7 & 100 \\
\hline & bersedia & Kadang & 0 & 0 \\
\hline & membantu & Tidak & 0 & 0 \\
\hline & $\begin{array}{l}\text { setiap } \\
\text { permasalahan }\end{array}$ & & & \\
\hline & klien & & & \\
\hline \multirow[t]{3}{*}{3} & Petugas & $\mathrm{Ya}$ & 5 & 71,4 \\
\hline & mengenal klien & Kadang & 2 & 28,6 \\
\hline & dengan baik & Tidak & 0 & 0 \\
\hline \multirow[t]{5}{*}{4} & Dilaksanakan & $\mathrm{Ya}$ & 0 & 0 \\
\hline & pertemuan & Kadang & 0 & 0 \\
\hline & berkala seluruh & Tidak & 7 & 100 \\
\hline & $\begin{array}{ll}\text { staf VCT } & 1 \\
\text { bulan sekali }\end{array}$ & & & \\
\hline & Total & & 7 & 100 \\
\hline
\end{tabular}

Hasil penelitian menunjukkan petugas selalu mendengarkan keluhan klien dengan baik, bersedia membantu permasalahan klien, dan tidak dilaksanakan pertemuan berkala dengan seluruh staf layanan VCT satu bulan sekali.

f. Kontinuitas

Tabel 8. Distribusi Jawaban Responden terhadap Kontinuitas Pelayanan VCT HOMA-B $(p=0,017)$.

\begin{tabular}{|c|c|c|c|c|}
\hline No & Variabel & Kategori & $\begin{array}{l}\text { Juml } \\
\text { ah }\end{array}$ & $\begin{array}{l}\text { Persent } \\
\text { ase (\%) }\end{array}$ \\
\hline \multicolumn{5}{|c|}{ Petugas VCT } \\
\hline \multirow[t]{3}{*}{1} & Pengulangan & $\mathrm{Ya}$ & 7 & 100 \\
\hline & tindakan yang & Kadang & 0 & 0 \\
\hline & $\begin{array}{l}\text { tidak diperlukan } \\
\text { klien }\end{array}$ & Tidak & 0 & 0 \\
\hline \multirow[t]{3}{*}{2} & Pencatatan & $\mathrm{Ya}$ & 7 & 100 \\
\hline & hasil & Kadang & 0 & 0 \\
\hline & $\begin{array}{l}\text { pemeriksaan } \\
\text { klien dan } \\
\text { disimpan } \\
\text { dengan baik }\end{array}$ & Tidak & 0 & 0 \\
\hline \multicolumn{5}{|c|}{ Petugas Manager kasus } \\
\hline \multirow[t]{3}{*}{1} & Selalu menggali & $\mathrm{Ya}$ & 5 & 71,4 \\
\hline & kebutuhan klien & Kadang & 2 & 28,6 \\
\hline & & Tidak & 0 & 0 \\
\hline \multirow[t]{3}{*}{2} & Melakukan & $\mathrm{Ya}$ & 0 & 0 \\
\hline & rujukan ke & Kadang & 0 & 0 \\
\hline & sarana & Tidak & 7 & 100 \\
\hline
\end{tabular}




\begin{tabular}{|c|c|c|c|c|}
\hline & \multicolumn{4}{|l|}{$\begin{array}{l}\text { pelayanan } \\
\text { kesehatan yang } \\
\text { dibutuhkan } \\
\text { klien }\end{array}$} \\
\hline \multicolumn{5}{|c|}{ Ketua Tim Mutu dan Kepala Klinik VCT } \\
\hline 1 & $\begin{array}{l}\text { Monitoring dan } \\
\text { evaluasi } \\
\text { layanan VCT }\end{array}$ & $\begin{array}{l}\text { Ya } \\
\text { Kadang } \\
\text { Tidak }\end{array}$ & $\begin{array}{l}0 \\
0 \\
7\end{array}$ & $\begin{array}{c}0 \\
0 \\
100\end{array}$ \\
\hline 2 & $\begin{array}{l}\text { Perbaikan dan } \\
\text { peningkatan } \\
\text { layanan }\end{array}$ & $\begin{array}{l}\text { Ya } \\
\text { Kadang } \\
\text { Tidak }\end{array}$ & $\begin{array}{l}0 \\
0 \\
7\end{array}$ & $\begin{array}{c}0 \\
0 \\
100\end{array}$ \\
\hline & Total & & 7 & 100 \\
\hline
\end{tabular}

Hasil penelitian menunjukkan petugas VCT tidak melakukan pengulangan tindakan yang tidak diperlukan klien, selalu mencatat hasil pemeriksaan dan menyimpannya dengan baik. Petugas manager kasus selalu melakukan rujukan ke sarana pelayanan kesehatan yang dibutuhkan dan kadang menggali kebutuhan klien. Monitoring dan evaluasi layanan VCT selalu dilakukan ketua tim mutu dan kadang kepala VCT melakukan monitoring dan evaluasi.

g. Keamanan

Tabel 9. Distribusi Jawaban Responden terhadap Keamanan

\begin{tabular}{lllcc}
\hline No & Variabel & Kategori & $\begin{array}{c}\text { Jumla } \\
\mathrm{h}\end{array}$ & $\begin{array}{c}\text { Persent } \\
\text { ase }(\%)\end{array}$ \\
\hline 1 & Klien & Ya & 7 & 100 \\
& $\begin{array}{l}\text { mendapat } \\
\text { pelayanan } \\
\text { yang aman }\end{array}$ & Tidak & 0 & 0 \\
& & & \\
\hline 2 & Penggunaan & Ya & 5 & 71,4 \\
& alat pelindung & Tidak & 2 & 28,6 \\
\hline 3 & Petugas & Ya & 7 & 100 \\
& menjaga & Tidak & 0 & 0 \\
& kerahasiaan & & & \\
& klien & & & 100 \\
\hline & Total & & 7 & \\
\hline
\end{tabular}

Hasil penelitian menunjukkan klien mendapat pelayanan yang aman cukup sesuai dengan pedoman, petugas menggunakan alat pelindung terutama dalam menangani pasien TB/rawat luka, dan selalu menjaga kerahasiaan dan privasi klien.

h. Kenyamanan

Tabel 10. Distribusi Jawaban Responden terhadap Kenyamanan

\begin{tabular}{lllcc}
\hline No & Variabel & Kategori & $\begin{array}{c}\text { Jumla } \\
\mathrm{h}\end{array}$ & $\begin{array}{c}\text { Persent } \\
\text { ase }(\%)\end{array}$ \\
\hline 1 & Kebersihan & Baik & 0 & 0 \\
& dan & Kurang & 5 & 71,4 \\
\hline
\end{tabular}

\begin{tabular}{lllcc}
\hline & $\begin{array}{l}\text { kenyamanan } \\
\text { ruang } \\
\text { pelayanan } \\
\text { dengan baik }\end{array}$ & Tidak & 2 & 28,6 \\
& & & \\
\hline 2 & Kenyamanan & Baik & 1 & 14,3 \\
& $\begin{array}{l}\text { dan kebersihan } \\
\text { fasilitas ruang } \\
\text { tunggu }\end{array}$ & Kurang & 4 & 57,1 \\
& Tidak & 2 & 28,6 \\
\hline 3 & Kelengkapan & Baik & 2 & 28,6 \\
& $\begin{array}{l}\text { dan kondisi } \\
\text { fasilitas dan }\end{array}$ & Kurang & 5 & 71,4 \\
& Tidak & 0 & 0 \\
& $\begin{array}{lll}\text { peralatan } \\
\text { medis }\end{array}$ & & & \\
\hline 4 & Kecepatan & Baik & 7 & 100 \\
& $\begin{array}{l}\text { waktu } \\
\text { tunggu/pelayan } \\
\text { an klien }\end{array}$ & Kurang & 0 & 0 \\
& Tidak & 0 & 0 \\
\hline & Total & & 100 \\
\hline
\end{tabular}

Hasil penelitian menunjukkan kebersihan dan kenyamanan gedung, ruang pelayanan, toilet masih kurang, kelengkapan dan kondisi fasilitas dan peralatan medis masih kurang. Sedangkan kecepatan waktu tunggu atau waktu pelayanan klien sudah baik/cepat.

\section{Pembahasan}

a. Gambaran Input Pelayanan VCT

Input pelayanan VCT meliputi man, money, materials, dan method. Ketersediaan SDM tidak memenuhi pedoman pelayanan VCT sehingga mengakibatkan adanya double job. Beban kerja petugas di puskesmas cukup besar dan menyebabkan pelayanan yang diberikan menjadi tidak maksimal [2]. Perlunya tambahan petugas sangat penting untuk memaksimalkan pelayanan yang diberikan. Sebagaian besar responden memiliki pengetahuan sedang tentang layanan VCT. Semakin tinggi pengetahuan maka kinerja karyawan akan semakin meningkat juga [3]. Instansi yang ingin berkembang harus memberikan perhatian terhadap pelatihan bagi karyawannya guna meningkatkan kinerja sehingga menghasilkan layanan bermutu [4]. Mayoritas petugas VCT telah mengikuti pelatihan dan memiliki sertifikat pelatihan.

Sumber biaya untuk pelayanan VCT berasal dari BOK, Global Fund, dan KPA. Responden menyatakan ketersediaan biaya untuk masih belum mencukupi untuk pengadaan pelatihan, penambahan SDM, transportasi pendampingan, pengadaan sarana yang kurang, dan perbaikan sarana prasarana.. Dana yang kurang atau ketiadaan anggaran akan berdampak pada kinerja karena kurangnya motivasi dalam menyelesaikan pekerjaan sesuai 
dengan tugasnya [5].

Materials merupakan aspek yang perlu diperhatikan sebab karyawan akan bekerja dengan optimal apabila didukung oleh sarana dan prasarana yang memadai [6]. Keterbatasan sarana akan sangat berpengaruh dalam proses pelayanan karena VCT merupakan pelayanan yang mengutamakan kenyamanan dan privasi klien. Pelayanan VCT di klinik VCT Puskesmas Puger masih banyak kendala yang ada seperti pintu masuk dan keluar yang seharusnya dibedakan namun masih satu pintu, ruang konseling dan ruang tunggu kurang nyaman, tidak tersedia bed pemeriksaan fisik, materi KIE tidak mencukupi, dan terbatasnya ARV di puskesmas. Sarana yang mengalami masalah akan menghambat aktivitas kerja petugas. Oleh sebab itu pemeliharaan sarana dan prasarana yang sudah tersedia dalam keadaan layak perlu diperhatikan dan dilakukan agar terjaga kualitasnya [7].

Metode yang digunakan ialah SOP pelayanan berupa pedoman internal pelayanan VCT yang mengacu pada Permenkes RI Nomor 74 Tahun 2014 dan Kepmenkes RI Nomor 1507/MENKES/SK/X/2015. Petugas telah memberikan pelayanan VCT sesuai dengan SOP yang ditetapkan dan dilakukan monitoring kinerja untuk memastikan kesesuaian SOP dengan pelayanan yang diberikan. SOP menjadi relevan karena sebagai tolak ukur efektivitas dan efisiensi kinerja instansi dalam melaksanakan program kerjanya [8]. Terdapat pengaruh positif dan signifikan antara SOP dan pengawasan terhadap variabel kinerja [9].

\section{b. Gambaran Proses Pelayanan VCT}

Proses pada pelayanan VCT meliputi planning, organizing, actuating, dan controlling. Perencanaan berupa strategi dalam mencapai tujuan program dan pelayanan VCT. Strategi yang dilakukan berdasarkan POA 2018 antara lain home visit pasien ODHA, pertemuan rutin KDS, internal meeting petugas. Namun belum terdapat perencanaan terkait penambahan SDM, perbaikan dan penambahan sarana prasarana yang belum tersedia. Perencanaan dapat meminimalkan resiko kegagalan dalam organisasi dan ketidakpastian tindakan dengan mengasumsikan kondisi di masa mendatang dan menganalisis konsekuensi dari setiap tindakan yang akan dilaksanakan [10].

Pengorganisasian dalam penelitian meliputi pembagian kerja dan koordinasi. Hasil penelitian sudah terdapat pembagian kerja untuk masing-masing petugas, struktur organisasi dan dokumen tertulis terkait job description masing-masing petugas. Uraian jabatan berpengaruh signifikan seacara parsial terhadap kinerja pegawai. Apabila pegawai memiliki jabatan yang jelas di suatu organisasi maka akan memberikan kontribusi kerjanya secara positif, sehingga akan dapat mengemban tugas dan tanggung jawab dengan maksimal [11]. Koordinasi pada pelaksanaan program pelayanan VCT selalu dilakukan. Tanpa adanya koordinasi setiap pekerjaan, maka tujuan program tidak akan tercapai. Dengan adanya koordinasi yang jelas dan merata maka persepsi dan pemahaman petugas akan sama.

Pelaksanaan pelayanan VCT sesuai Permenkes RI Nomor 74 Tahun 2014 meliputi konseling pra testing, informed concent, testing HIV, dan konseling pasca testing. Konseling pra testing tidak dilakukan pada mobile VCT ke populasi kunci dan tes HIV atas inisiasi petugas. Pentingnya konseling pra testing untuk mendiskusikan hal terkait informasi HIV-AIDS, perilaku beresiko, testing HIV, serta membangun kepercayaan klien pada konselor yang merupakan dasar utama bagi terjaganya kerahasiaan sehingga terjalin hubungan baik dan saling memahami. Sementara, konseling pasca testing hanya dilakukan pada klien positif (reaktif) saja. Konseling pasca testing sangat penting untuk membantu klien memahami dan menyesuaikan diri dengan hasil testing serta mengajak klien mendiskusikan strategi untuk menurunkan penularan HIV. Oleh karena itu, perlu dilakukan konseling pra testing dan pasca testing bagi semua klien guna mengedukasi dan menurunkan resiko penularan HIV-AIDS [12].

Pada penelitian ini pengawasan terdiri dari evaluasi dan supervisi. Evaluasi berkala (sebulan/tiga bulan sekali) terkait evaluasi yang berhubungan dengan keluhan klien, tindakan keberlanjutan program, sedangkan evaluasi tidak terjadwal dilakukan apabila ada kendala dalam proses berjalannya program pada hari itu sehingga tidak terjadi kendala yang sama. Evaluasi dapat membantu pengembangan, implementasi, kebutuhan, perbaikan program, pertanggungjawaban, motivasi, menambah pengetahuan dan dukungan agar program sesuai dengan yang telah direncanakan. Supervisi sudah dilakukan baik oleh kepala puskesmas, kepala klinik VCT, maupun koordinator tim mutu setiap satu bulan sekali. Kegiatan supervisi sangat berpengaruh terhadap kinerja petugas. Adanya pengaruh yang kuat antara supervisi dari atasan terhadap kinerja petugas kesehatan [13]. Meskipun sudah 
ada supervisi, tetapi sebaiknya supervisi dilakukan secara berkala agar kinerja petugas menjadi lebih baik lagi.

\section{c. Gambaran Output Pelayanan VCT}

Output penelitian berupa pelayanan VCT berdasarkan dimensi mutu kompetensi teknis, akses terhadap layanan, efektivitas, efisiensi, hubungan antar manusia, kontinuitas, keamanan, dan kenyamanan. Kompetensi teknis yang dimaksud ialah hal menyangkut keterampilan, kemampuan, penampilan, kinerja, kepatuhan, ketepatan dan konsistensi petugas VCT dalam mengikuti standar pelayanan yang telah ditetapkan. Pendidikan petugas VCT sudah memenuhi standar pendidikan Kepmenkes RI Nomor 1507/MENKES/SK/X/2015. Mayoritas petugas pelayanan VCT telah mengikuti pelatihan walaupun masih kurang bagi sebagian petugas. Tujuan pelatihan dalam usahanya untuk meningkatkan kinerja karyawan sehingga menghasilkan layanan yang berkualitas/bermutu. Oleh karena itu, untuk meningkatkan keahlian yang berujung pada peningkatan kinerja, diperlukan adanya pelatihan dan orientasi kepada pegawai. Kemampuan, keterampilan, dan kejelasan informasi yang diberikan petugas VCT kepada klien sudah baik, terutama konselor. Semua petugas VCT selalu mendengarkan keluhan klien serta selalu berpenampilan bersih dan rapi dalam memberikan pelayanan sehingga klien merasa nyaman dan dihargai. Dalam memberikan pelayanan masih terdapat beberapa yang kurang sesuai dengan tupoksi, misalnya pengambilan darah klien untuk testing dilakukan oleh petugas manager kasus yang bukan berlatarpendidikan perawat. Petugas VCT melaksanakan setiap tahapan pelayanan yang cukup sesuai dengan pedoman. Pasien akan merasa puas apabila kinerja layanan kesehatan yang diperolehnya sama atau melebihi harapannya [14]. Petugas kesehatan punya tanggung jawab moral untuk memberikan tanggapan yang cepat, akurat dan dilandasi empati [15].

Akses terhadap layanan meliputi aspek geografis, ekonomi, dan kemudahan prosedur pelayanan. Aspek geografis, lokasi puskesmas Puger strategis, mudah dijangkau dan dapat ditempuh semua jenis kendaraan bermotor. Terdapat hubungan yang positif antara jarak dengan pemanfaatan pelayanan kesehatan dimana semakin dekat suatu fasilitas kesehatan, semakin tinggi kemauan pasien untuk berkunjung [16]. Aspek ekonomi, klien tidak dibebankan biaya sehingga semua masyarakat dengan mudah menjangkau dan memanfaatkan layanan VCT. Kemudahan prosedur mendapatkan pelayanan sangat penting bagi pengguna layanan untuk menyampaikan kritik, pertanyaan dan keluhannya. Berdasarkan penelitian, kemudahan klien menghubungi petugas dalam kategori cukup, namun beberapa petugas sulit dihubungi klien dan nomor telepon pengaduan klien belum tersedia. Sedangkan untuk kemudahan prosedur pelayanan, klien sudah langsung dapat melihat alur pelayanan dan bertanya petugas jika mengalami kesulitan.

Mutu pelayanan tergantung dari efektivitas menyangkut norma pelayanan kesehatan dan petunjuk klinis sesuai standar yang ada. Penanganan dan perawatan sesuai kebutuhan klien, tahap pelayanan VCT yang dilakukan cukup sesuai pedoman. Ketepatan waktu jam pelayanan sebagian petugas VCT sudah tepat, namun masih terdapat kurangnya ketepatan kunjungan ke tempat klien oleh petugas manager kasus dan kecepatan pencatatan dan pelaporan petugas RR. Efektivitas terkait upaya pelayanan kesehatan perlu diselenggarakan agar sesuai dengan standar profesi serta pelayanan yang memuaskan pasien. Hal tersebut diperlukan untuk memenuhi tuntutan masyarakat yang semakin meningkat akan pelayanan kesehatan yang bermutu [17].

Efisiensi merupakan dimensi penting dari mutu karena efisiensi akan mempengaruhi hasil pelayanan kesehatan [18]. Ketersediaan SDM dan sarana kurang memadai, namun pelayanan VCT tetap dapat dilakukan dengan baik. Hal ini dikarenakan efisiensi dalam pelayanan dapat dilakukan dengan baik oleh petugas. Efisiensi layanan kesehatan dalam memberikan pelayanan tidak merugikan pasien dan tenaga kesehatan yang ada di dalamnya. Hasil observasi menunjukkan bahwa kecepatan pelayanan yang diberikan petugas VCT ke klien cukup cepat. Kepuasan pasien didapatkan salah satunya melalui kecepatan pelayanan yang diberikan oleh petugas dengan memberikan penanganan yang cepat [19].

Hubungan antar manusia yang baik dalam pelayanan VCT memberikan andil yang besar dalam konseling yang efektif [1]. Hasil observasi menunjukkan petugas selalu menyapa klien saat memasuki ruangan, senantiasa tersenyum dan melayani klien dengan sopan dan ramah. Petugas mampu memberikan informasi maupun menjelaskan hasil tes dengan bahasa yang mudah dimengerti klien. Berdasarkan observasi 
klien terlihat nyaman selama konseling berlangsung, konselor bersikap terbuka dan tidak menghakimi. Keterbukaan klien dan konselor merupakan kunci keberhasilan membangun hubungan konseling. Dengan membuka diri, konselor dapat menciptakan hubungan yang hangat dan akrab dengan konseli sehingga klien memperoleh kepuasan psikologis [20]. Terselenggaranya pelayanan kesehatan yang bermutu, hubungan antara petugas kesehatan pasien harus baik, petugas memberi perhatian cukup kepada kliien tanpa ada perbedaan, menampung dan mendengar semua keluhan klien sehingga tercipta hubungan antar manusia yang baik [21].

Kontinuitas pelayanan berarti klien akan menerima pelayanan lengkap yang dibutuhkan tanpa mengulangi prosedur diagnosis dan terapi yang tidak diperlukan. Tidak adanya kontinuitas pelayanan akan mengurangi efisiensi dan kualitas hubungan antar manusia [19]. Semua petugas VCT tidak melakukan pengulangan tindakan pelayanan yang tidak diperlukan klien, selalu melakukan pencatatan hasil pemeriksaan klien dan menyimpan catatan hasil pemeriksaan medis dengan baik. Petugas manager kasus selalu mengkoordinasi pelayanan komprehensif yang dibutuhkan klien, melakukan rujukan ke sarana pelayanan kesehatan yang dibutuhkan dan kadang menggali kebutuhan klien terkait kebutuhan psikologis dan sosial. Monitoring internal dan penilaian kinerja seluruh petugas dilakukan oleh ketua tim mutu, monitoring dan evaluasi selalu dilakukan oleh ketua tim mutu dan kadang kepala VCT juga melakukan monitoring dan evaluasi. Kontinuitas pelayanan akan memberikan kepuasan kepada pasien.

Kemanan sebagai salah satu dari mutu, dimana seluruh pengguna fasilitas percaya akan keselamatannya [19]. Klien mendapat pelayanan yang aman, terjaga kerahasiaan dan privasinya. Petugas VCT telah menerapkan pedoman dengan cukup baik walaupun masih terdapat yang belum sesuai pedoman pelayanan. Dalam memberikan pelayanan, petugas telah dibekali pengetahuan dan kemampuan teknis yang memadai. Karena dengan keamanan itu sendiri akan meringankan beban klien, setidaknya mengurangi tingkat kecemasan mereka akan penyakit yang menyerang mereka.

Kenyamanan ialah penerimaan klien terhadap kondisi yang dilihat dan dirasakan langsung klien yang menerima pelayanan VCT. Kebersihan dan kenyamanan ruang pelayanan VCT masih kurang, kelengkapan dan kondisi fasilitas dan peralatan medis masih kurang, sedangkan kecepatan waktu pelayanan yang diberikan kepada klien sudah baik/cepat. Ruang konseling cukup luas, namun penerangan kurang, ruangan terasa pengap, kondisi kursi konseling kurang nyaman. Selain itu, pintu masuk dan pintu keluar tidak dibedakan sehingga klien yang selesai konseling dan klien yang berikutnya yang akan konseling dapat saling bertemu. Walaupun ruang konseling kurang nyaman, petugas ramah dan mudah mengakrabkan diri sehingga klien merasa nyaman saat konseling. Kenyamanan menjadi faktor penting dalam memberikan kepuasan terutama industri jasa. Pasien merasa nyaman dengan pelayanan kesehatan akan memberikan penilaian baik tentang pelayanan kesehatan tempat tersebut dan menganggapnya sebagai pelayanan kesehatan yang bermutu [14].

\section{Simpulan dan Saran}

Ketersediaan SDM terutama konselor dan petugas manager kasus masih kurang, sehingga petugas merangkap pekerjaan lain. Pendanaan layanan VCT yang berasal dari BOK, Global Fund dan KPA masih belum mencukupi. Ketersediaan dan kondisi material berupa sarana dan prasarana masih belum memenuhi aspek dalam SOP pelayanan VCT. Perencanaan terkait penambahan SDM, perbaikan dan penambahan sarana prasarana belum tertulis dalam POA. Pembagian kerja sudah sesuai dengan tupoksi dan kompetensi masing-masing petugas VCT serta selalu dilakukan koordinasi, supervisi dan evaluasi. Pada pelaksanaan layanan VCT terdapat beberapa yang tidak dilaksanakan sesuai pedoman yakni pemberian informasi keuntungan diagnosis dini, konseling pasca testing untuk klien dengan hasil testing negatif/nonreaktif, dan informasi pendampingan, serta tidak dilakukan konseling pra testing pada layanan mobile VCT ke populasi kunci dan tes HIV atas inisiasi petugas. Pada dimensi kompetensi teknis, akses terhadap layanan, efisiensi, hubungan antar manusia, kontinuitas dan keamanan klinik VCT dalam kategori baik. Dimensi efektivitas pelayanan VCT dalam kategori cukup, masih terdapat kurangnya ketepatan dalam kunjungan ke tempat klien dan dalam hal kecepatan pencatatan dan pelaporan. Dimensi kenyamanan layanan VCT kurang baik, kebersihan dan kenyamanan ruang pelayanan maupun toilet masih kurang serta kurangnya kelengkapan dan kondisi fasilitas dan peralatan medis. 
Saran yang dapat diberikan adalah mengusulkan penambahan SDM di klinik VCT terutama konselor dan petugas manager kasus agar tidak terjadi double job sehingga dapat memaksimalkan pelayanan yang diberikan, penambahan dan perbaikan sarana dan prasarana agar memenuhi standar minimal yang harus ada di Klinik VCT, dan memperbaiki penataan ruangan pelayanan termasuk memisahkan pintu masuk dan keluar ruang konseling untuk meningkatkan kenyamanan petugas maupun klien dan menjaga privasi klien.

\section{Daftar Pustaka}

[1] Keputusan Menteri Kesehatan Republik Indonesia Nomor 1507/Menkes/SK/X/2005 tentang Pedoman Pelayanan Konseling dan Testing HIVIAIDS Secara Sukarela.

[2] Mujiati. Ketersediaan Sumber Daya Manusia Kesehatan pada Fasilitas Kesehatan Tingkat Pertama dalam Era Jaminan Kesehatan Nasional di Delapan KabupatenKota di Indonesia. Media Litbangkes. 2016 26(4):206.

[3] Suhartini, Y. Analisis Faktor-Faktor yang Mempengaruhi Minat Mahasiswa dalam Berwiraswasta. Jurnal Akmenika UPY. 2011. 7(1):24.

[4] Rudhaliawan, et al., Pengaruh Pelatihan Terhadap Kemampuan Kerja dan Kinerja Karyawan. Malang: UB; 2013.

[5] Muninjaya, A. Manajemen Kesehatan Edisi 2. Jakarta: Penerbit Buku Kedokteran EGC; 2004.

[6] Ikhsan, M. Pengaruh Manajemen Sarana Prasarana Terhadap Kinerja Pegawai di Badan Pendidikan dan Pelatihan Daerah BANDIKLATDA Provinsi Jawa Barat. Skripsi. Bandung: UPI; 2013.

[7] Arimawati, D. Pemeliharaan Sarana dan Prasarana Kantor di kantor Balai Pengembangan Kegiatan Belajar (BPKB) Daerah Istimewa Yogyakarta. Skripsi. Yogyakarta: UNY; 2015.

[8] Chrisyanti, Pengantar IImu Administrasi. Jakarta: PT Prestasi Pustakaraya; 2011.
[9] Nugraheni, et al. Pengaruh Standar Operasional Prosedur Dan Pengawasan Terhadap Kinerja Pramuniaga Pasaraya Sriratu Pemuda Semarang. Skripsi. Semarang: Undip; 2014.

[10] Badrudin. Dasar-dasar Manajemen. Bandung: Alfabeta; 2003.

[11] Tanumihardjo, et al., Pengaruh Analisis Jabatan terhadap Kinerja Pegawai. Jurnal. Malang: Universitas Brawijaya; 2014.

[13 Peraturan Menteri Kesehatan Republik Indonesia Nomor 74 Tahun 2014 tentang Pedoman Pelaksanaan Konseling dan Tes HIV.

[14] Renyaan, et al., Hubungan antara Insentif, Motivasi, Supervisi dengan Kinerja perawat di Ruang Rawat Inap RSUD Kabupaten Sorong. Jurnal. 2016. Vol 2 (6): 72

[15] Pohan, I. 2006. Jaminan Mutu Layanan Kesehatan: Dasar-Dasar Pengertian dan Penerapan.Jakarta: EGC.

[16] Muninjaya. Manajemen Mutu Pelayanan Kesehatan. Jakarta: EGC; 2012.

[17] Nainggolan, et al., Pengaruh Akses ke Fasilitas Kesehatan Terhadap Kelengkapan Imunisasi Baduta (Analisis Riskesdas 2013). Jurnal Media Litbangkes.2016. 26(1) : 15-28.

[18] Hartono. Efektivitas Sistem Pelayanan Kesehatan Masyarakat Oleh Dinas Kesehatan Kota Samarinda. Jurnal Administrasi Negara. 2016. 4(2) : 40274041.

[19] Bustami. Penjaminan Mutu Pelayanan Kesehatan dan Akseptabilitasnya. Jakarta: Erlangga; 2011.

[20] Tjiptono dan Gregorius. Service, Quality, \& Satisfication. Yogyakarta: Andi Offset; 2011.

[21] Wahyuni. Teori dan Teknik Konseling. Jakarta: Indeks; 2014.

[22] Satriani, et al. Studi Mutu Pelayanan Voluntary Counseling And Testing (VCT) Di Puskesmas Jongaya Makassar Tahun 2012. Jurnal Media Kesehatan Masyarakat Indonesia FKM UNHAS. 2012. 9(4). 